\title{
Body size information in large-scale acoustic bat databases
}

\author{
Caterina Penone ${ }^{\text {Corresp., }}{ }^{\text {, }}$, Christian Kerbiriou ${ }^{2,3}$ ， Jean-François Julien ${ }^{4}$, Julie Marmet ${ }^{4}$, Isabelle Le Viol ${ }^{3,4}$ \\ ${ }^{1}$ Institute of Plant Sciences, University of Bern, Bern, Switzerland \\ 2 CESCO UMR7204 MNHN-UPMC-CNRS-Sorbonne Université, Université Pierre et Marie Curie (Paris VI), Paris, France \\ ${ }^{3}$ Marine Station, Muséum national d'Histoire naturelle, Concarneau, France \\ ${ }^{4}$ CESCO UMR7204 MNHN-UPMC-CNRS-Sorbonne Université, Muséum national d'Histoire naturelle, Paris, France \\ Corresponding Author: Caterina Penone \\ Email address: caterina.penone@gmail.com
}

Background. Citizen monitoring programs using acoustic data have been useful for detecting population and community patterns. However, they have rarely been used to study broad scale patterns of species traits. We assessed the potential of acoustic data to detect broad scale patterns in body size. We compared geographical patterns in body size with acoustic signals in the bat species Pipistrellus pipistrellus. Given the correlation between body size and acoustic characteristics, we expected to see similar results when analyzing the relationships of body size and acoustic signals with climatic variables.

Methods. We assessed body size using forearm length measurements of 1359 bats, captured by mist nets in France. For acoustic analyses, we used an extensive dataset collected through the French citizen bat survey. We isolated each bat echolocation call (n $=4783$ ) and performed automatic measures of signals, including the frequency of the flattest part of the calls (characteristic frequency). We then examined the relationship between forearm length, characteristic frequencies, and two components resulting from principal component analysis for geographic (latitude, longitude) and climatic variables. Results. Forearm length was positively correlated with higher precipitation, lower seasonality, and lower temperatures. Lower characteristic frequencies (i.e., larger body size) were mostly related to lower temperatures and northern latitudes. While conducted on different datasets, the two analyses provided congruent results. Discussion. Acoustic data from citizen science programs can thus be useful for the detection of large-scale patterns in body size. This first analysis offers a new perspective for the use of large acoustic databases to explore biological patterns and to address both theoretical and applied questions. 


\section{Body size information in large-scale acoustic bat databases}

3 Authors: Caterina Penone ${ }^{1}$, Christian Kerbiriou ${ }^{2,3}$, Jean-François Julien ${ }^{4}$, Julie Marmet ${ }^{4}$, Isabelle

4 Le $\mathrm{Viol}^{2,4}$

5

6 Affiliations :

$7 \quad{ }^{1}$ Institute of Plant Sciences, University of Bern, Switzerland

$8 \quad{ }^{2}$ CESCO UMR7204 MNHN-UPMC-CNRS-Sorbonne Université, Université Pierre et Marie

9 Curie (Paris VI), Paris, France

$10{ }^{3}$ Marine Station, Muséum National d'Histoire Naturelle, Concarneau, France

$11{ }^{4}$ CESCO UMR7204 MNHN-UPMC-CNRS-Sorbonne Université, Muséum National d'Histoire

12 Naturelle, Paris, France

\section{Corresponding author:}

16 Caterina Penone

17 caterina.penone@gmail.com

18 Institute of Plant Sciences, University of Bern, Switzerland

19 Altenbergrain 21 - 3013 Bern, Switzerland 


\section{Abstract}

23 Background. Citizen monitoring programs using acoustic data have been useful for detecting

24 population and community patterns. However, they have rarely been used to study broad scale

25 patterns of species traits. We assessed the potential of acoustic data to detect broad scale patterns

26 in body size. We compared geographical patterns in body size with acoustic signals in the bat

27 species Pipistrellus pipistrellus. Given the correlation between body size and acoustic

28 characteristics, we expected to see similar results when analyzing the relationships of body size

29 and acoustic signals with climatic variables.

30 Methods. We assessed body size using forearm length measurements of 1359 bats, captured by

31 mist nets in France. For acoustic analyses, we used an extensive dataset collected through a

32 citizen science program for bats. We isolated each bat echolocation call $(n=4783)$ and

33 performed automatic measures of signals, including the frequency of the flattest part of the calls

34 (characteristic frequency). We then examined the relationship between forearm length,

35 characteristic frequencies, and two components resulting from principal component analysis for

36 geographic (latitude, longitude) and climatic variables.

37 Results. Forearm length was positively correlated with higher precipitation, lower seasonality,

38 and lower temperatures. Lower characteristic frequencies (i.e., larger body size) were mostly

39 related to lower temperatures, lower seasonality and northern latitudes. While conducted on

40 different datasets, the two analyses provided similar results. 
41 Discussion. Acoustic data from citizen science programs can thus be useful for the detection of

42 large-scale patterns in body size. This first analysis offers a new perspective for the use of large

43 acoustic databases to explore biological patterns and to address both theoretical and applied

44 questions. 


\section{Introduction}

47 Acoustic methods can be used for biodiversity assessment (Riede, 1998; Johnston et al., 2008;

48 Newson et al., 2015) and a large amount of sound data is available in repositories, and through

49 large-scale citizen science programs (Walters et al., 2012; Jones et al., 2013; Penone et al., 2013;

50 Newson et al., 2017). Improved computational facilities and new algorithms now enable acoustic

51 data to be recorded and analyzed automatically to identify species and collect information on

52 each recorded individual (Bardeli et al., 2010; Walters et al., 2012; Jones et al., 2013; Newson et

53 al., 2017). Despite their high potential, acoustic databases have rarely been used to explore trait

54 patterns across large spatial extents (Law et al., 2002, but see Murray et al., 2001). Here, we

55 examined whether acoustic data collected by a citizen science program might be used to detect

56 broad scale patterns in species traits, focusing on body size.

57 Body size is closely related to many physiological, life history, and ecological parameters

58 (Peters, 1986). At a macroecological scale, this trait is linked to species ranges, abundances, co-

59 occurrences, and energy use (Brown, 1995; Barnagaud et al., 2014). Therefore, assessing broad

60 scale patterns in body size can help in understanding how resources and diversity are partitioned

61 in space and time, as well as life history evolution.

62 For a number of taxonomic groups, geographic variation in body size within species has been

63 related to latitude and climatic variables such as temperature and precipitation (Bergmann's and

64 James' rules: Bergmann, 1847; James, 1970). Organisms generally show increased body size or 
65 mass at higher latitudes, in colder and wetter climates, and where there is increased productivity

66 or food availability (Rosenzweig, 1968; Ashton et al., 2000; Freckleton et al., 2003; Meiri \&

67 Dayan, 2003; Yom-Tov \& Geffen, 2006; McNab, 2010; Clauss et al., 2013). Even if originally

68 described among closely-related species of homeotherms, it is now recognized that such

69 macroecological rules also apply at the intraspecific level (Ashton et al., 2000). At the

70 intraspecific level, adult body size is also partly related to food availability during early-stage

71 growth (Henry \& Ulijaszek, 1996; Lindström, 1999). Here we analyzed the geographic variation

72 in body size of Pipistrellus pipistrellus (Schreber, 1774), a common and sedentary bat species of

73 the Vespertilionidae family, which is widely distributed and abundant in several European

74 habitats, includingFrance (Davidson-Watts et al., 2006, Mitchell-Jones et al., 1999).

75 The link between body size and climatic variables at the intraspecific level has already been

76 highlighted in some Vespertilionidae species (e.g., Burnett, 1983; Ashton et al., 2000; Meiri \&

77 Dayan, 2003), but the validity of the rule for P. pipistrellus has not yet been demonstrated

78 (Stebbings, 1973; Jones et al., 1993). For a large number of species, communication sound

79 frequency is negatively correlated with body size (Gillooly and Ophir, 2010; Thiagavel et al.,

80 2017). For many echolocating bats, the peak frequency (i.e., the frequency of maximum energy),

81 and the characteristic frequency (i.e., the frequency of the flattest part of the echolocation call,

82 Kalko \& Schnitzler, 1993)), have been shown to be negatively correlated with body size (Barclay

83 \& Brigham, 1991; Jones, 1999; Jakobsen et al., 2013; Jung et al., 2014; Thiagavel et al., 2017). 
84 Even at the intraspecific level, smaller individuals emit signals of higher frequency than larger

85 ones, a trend that has been mostly attributed to allometric constraints and to the size of the target,

86 i.e., prey (Barclay \& Brigham, 1991; Jones, 1999; Gillooly \& Ophir, 2010; Thiagavel et al.,

87 2017). Allometric constraints imply that larger bats produce lower frequency sounds because

88 they have a bigger larynx and larger resonant chambers (Jacobs et al., 2007). This negative

89 correlation between body size and characteristic frequency is particularly strong in the

90 Vespertilionidae family (Jones, 1999; Thiagavel et al., 2017). However, this pattern is not valid

91 for all bat species, such as most of the so-called constant frequency bats (Russo et al., 2001),

92 because of important differences in the mechanisms involved in their echolocation modalities. $P$.

93 pipistrellus does not belong to this group of species and is therefore a potentially interesting

94 model species to explore biogeographic patterns, using characteristic frequencies as a proxy for

95 body size.

96 To assess whether large-scale patterns in body size are detectable using bat echolocation

97 frequencies, we (i) studied the geographic variation in body size of P. pipistrellus and its

98 environmental correlates, using forearm length measurements, which are proportional to body

99 size (Thiagavel et al., 2017). We then (ii) examined the same relationships using the

100 characteristic frequency of $P$. pipistrellus. Given the negative relationship between characteristic

101 frequencies and body size (Thiagavel et al., 2017), we expected to see similar relationships 
102 between forearm lengths and characteristic frequencies, and geographic and environmental

103 variables.

104

\section{Materials \& methods}

106 Mist net dataset

107 In order to relate body size characteristics to geographic (latitude, longitude) and climatic

108 variables for P. pipistrellus we assembled several datasets obtained from mist net bat captures

109 and measurements in continental France. Data were collected by bat workers for local

110 conservation studies and inventories from April to July over a 4 year period (2009-2012),

111 representing 208 observations in 186 localities. Forearm length was measured with calipers and

112 was used as a measure of body size. Forearm length is roughly proportional to the mass of the

113 individual with a 0.3 ratio in Vespertilionids (Norberg, 1981; Thiagavel et al., 2017) and this was

114 confirmed by our data (see Appendix A3). However, in contrast to body mass, forearm length is

115 not subject to seasonal or reproductive changes and is therefore a more reliable proxy of body

116 size (Thiagavel et al., 2017). Species identification, sex, reproductive status, and age estimation

117 were assessed in the field according to Dietz \& von Helversen (2004). We removed from our

118 dataset juveniles and individuals for which we did not have sex information. Bats were captured

119 by bat workers under license from the French Ministry of Environment. All captures were made

120 according to the code of ethics drafted as part of the national training system for the capture of 
121 bats (MNHN \& SFEPM, 2015). Individuals were released immediately after they had been

122 measured; therefore, the acoustic parameters of the captured individuals are not available for this

123 dataset. This is a limitation of our study, however, obtaining frequency information for each

124 captured individual would have been challenging because such recordings have to be done under

125 laboratory conditions given that hand-released bats usually provide atypical calls (Britzke, 2004).

126 Acoustic dataset and sound analyses

127 To examine the relationship between acoustic data and geographic and climatic variables we

128 used a dataset provided by the French national bat monitoring program (Vigie-Chiro), a citizen

129 science program coordinated by the French National Museum of Natural History (Kerbiriou et

130 al., 2018, Appendix A1). Observers completed two surveys in June to July and August to

131 September 2009, along the same 30-km circuits. Each circuit was divided into ten 2-km road

132 segments, separated by $1-\mathrm{km}$ road segments in which no records were made.

133 We analyzed the results from 76 of these $30-\mathrm{km}$ circuits, for which we had complete data on

134 each variable (see variable descriptions below and Fig. 1).

135 We used Scan'R software (version 1.5, Binary Acoustic Technology, Tucson, Arizona,

136 USA) to isolate each $P$. pipistrellus call and perform automatic extraction of signal parameters

137 (Appendix A1). Very low quality calls were automatically filtered out by Scan'R, which was set

138 up to remove false detections due to noises such as rain drops or static discharging ("pop filter",

139 in Scan'R manual, Binary Acoustic Technology LLC, 2009). Furthermore, we retained only 
140 signals longer than $1 \mathrm{~ms}$ and set the "fit restricted" parameter to "medium" (i.e. all detections are

141 required to match the internal curve model, with some tolerance for error, see Scan'R manual,

142 Binary Acoustic Technology LLC, 2009). A manual inspection of around 50 randomly chosen

143 signals confirmed us that they were indeed from $P$. pipistrellus. Analyses were performed using

144 the LowFc (hereafter "characteristic frequency"), which is the frequency at the end of the

145 shallowest modulated part of the calls (Kalko \& Schnitzler, 1993; Appendix Fig. A2.1). In order

146 to avoid potential misidentification of P.pipistrellus we selected only calls with a LowFc

147 between 41 and $52 \mathrm{kHz}$ (Barataud et al., 2015; Appendix 2). We also extracted the slope of the

148 quasi-constant frequency (QCF) characteristic part of the acoustic signal ("SlopeQCF”, Fig.

149 A2.1). This value has been shown to be correlated to frequency, and is higher (i.e., more

150 negative) in cluttered habitats (i.e., habitats with closed and dense vegetation) compared to open

151 habitats, including for $P$. pipistrellus (Kalko \& Schnitzler, 1993). This means that bats emit

152 higher calls with a steeper slope (i.e., higher values of SlopeQCF) when flying in cluttered

153 habitats (Kalko \& Schnitzler, 1993). In open habitats, their calls have a much shallower

154 frequency modulation (corresponding to low values of SlopeQCF) and lower frequencies (Kalko

$155 \&$ Schnitzler, 1993). This was verified by our data (see Appendix A2 for a detailed description).

156 Studies considering geographical variation in echolocation calls might be affected by the clutter

157 conditions in the sample areas (O'Farrell et al., 2000). We thus included SlopeQCF in our 
158 models, to take into account the effect of habitat clutter at a local scale on the characteristics of

159 echolocation signals.

160

161 Geographic and climatic variables

162 Latitude has been used as a proxy for temperature in several biogeography studies (e.g.

163 Ashton et al., 2000). However, climatic variables other than temperature (e.g., rainfall) covary

164 with latitude and might be related to body size. We extracted data on climatic variables for both

165 mist net points and acoustic data segments from WorldClim 1.4 (Hijmans et al., 2005). We

166 selected the annual mean temperature (Bio1), annual temperature range (Bio7, an index of

167 seasonality), mean temperature of the warmest and coldest quarters (Bio10 and Bio11,

168 respectively), annual precipitation (Bio12), and precipitation of the wettest quarter (Bio16).

169 Because body size patterns might reflect climatic variations at large temporal scales (Brown \&

170 Maurer, 1989), we used averaged WorldClim variables across 30 years (1960-1990). Although

171 this information does not overlap our recording and capture periods, it is usually considered as

172 representative of current climatic conditions in several studies (e.g. Machac et al. 2011; Hassall

173 et al. 2014). Since climatic variables tend to covary in space, we used a principal component

174 analysis (PCA) to combine the information on geographic (latitude and longitude) and climatic

175 variables. All variables were scaled prior to PCA. We also measured the mean altitude in each

176 segment and mist net point, using a digital elevation model at 250m resolution (BD-Alti IGN). 
178 Statistical analyses

179 Altitude might have an effect on body size (Meiri \& Dayan, 2003); therefore, we restricted the

180 analysis to points below $500 \mathrm{~m}$ and removed island data to avoid insularity issues. Since data

181 collected before 2009 might contain spurious identifications owing to confusion with $P$.

182 pygmaeus (Mayer \& von Helversen, 2001), we considered only data collected after this date, for

183 which identification of $P$. pipistrellus was reliable.

184 We fitted linear mixed-effects models (lme4, lmerTest (Bates et al., 2015; Kuznetsova et

185 al., 2017) in R (R Core Team, 2013) to determine if forearm length and characteristic frequencies

186 (response variables) were related to latitude and large-scale climatic variables, represented by

187 principal components. In the model with mist net data, we corrected for the day of the year in

188 which the bats were captured, and for the sex of the individual by adding these variables as

189 covariates (see Appendix A3 for more details on the effect of sex). We included the name of the

190 locality where the individuals were captured, nested into the year of capture as random effect, to

191 account for temporal and spatial structure of the data. Given the high concentration of data points

192 in the northwestern part of France, in order to check for potential bias in our analysis, we

193 repeated the model on a subset which included only the northwestern points (see Appendix A4

194 for more details). 
196 the slope of the quasi-constant frequency (SlopeQCF) of each detected acoustic signal. Given

197 that several bat species, including P. pipistrellus, tend to modify their calls in order to avoid

198 interference with calls of conspecifics (also called jamming avoidance, Necknig \& Zahn, 2011;

199 Ulanovsky et al., 2004), we incorporated the number of calls within a $400 \mathrm{~m}$ section into the

200 models (call abundance), as a proxy for the number of individuals. Segments nested into each

201 circuit were included as a random effect, to take into account the spatial structure of the data.

202 The local temperature during recording sessions might have influenced call detection; however,

203 we only had information on this parameter for 44 circuits out of 76 . Therefore, we ran the

204 analysis on these 44 circuits ( $n=1705$ calls), in order to assess the importance of temperature

205 during recording sessions, and its potential bias on our results (Appendix A5). The day of the

206 year in which the bats were recorded could potentially be more informative than the survey

207 period, but we had information for $45 \%$ of the data points; we thus tested the effect of the date of

208 recording on this data subset. Given the high concentration of data points in the northern part of

209 France, we repeated the model on a subset including only the central northern points (Appendix

210 A4). We also ran the analyses on the southern points only, to check for potential species

211 identification issues (further details in Appendix A4).

212 Finally, given that females tend to be bigger than males (Appendix A3), variation in the

213 sex ratio across the climatic gradient might affect the results for the acoustic dataset for which 
214 we do not have information on the sex of individuals. We visually checked all models for

215 normality in model residuals and heteroscedasticity (see R script:

$216 \mathrm{https}: / /$ github.com/caterinap/pipip_frequency_bodysz).

217

\section{Results}

219 We analyzed mist net data for 1359 individuals. Forearm length of $P$. pipistrellus varied between

22027.6 and $37.4 \mathrm{~mm}$ (mean $31.6 \pm 0.96 \mathrm{SD}$ ). The number of individuals captured per location and

221 per year varied between 1 and 52 (mean $6.5 \pm 6.1 \mathrm{SD}$ ).

222 Along the 69 circuits with available acoustic and environmental data, we analyzed 4783 calls of

223 P. pipistrellus. The characteristic frequency varied between 42.1 and $51.9 \mathrm{KHz}$ (mean $46.9 \pm 1.9$

224 SD). The number of recorded calls per segment varied between 1 and 71 (mean $23.5 \pm 17.7 \mathrm{SD}$ ).

226 Geographic and climatic variables and the acoustic (A.PC1 and A.PC2) datasets summarized $87 \%$ and $93 \%$ of the variation in geographic and climatic variables, respectively (Fig.2 and Table 1). As shown by variable

230 loadings for the principal components (Fig.2 and Table 1), M.PC1 and A.PC1 mostly included

231 information about longitude, temperature variability, and precipitation in both datasets. High

232 M.PC1 or A.PC1 values represented places with high precipitation (Bio12, Bio16), and low 
233 temperature range or seasonality (Bio7), principally located in western France. The secondary

234 principal component was more representative of latitude (especially for the acoustic dataset,

235 A.PC2) and temperature (Fig.2). High A.PC2 or M.PC2 values characterized places with high

236 temperatures in both the warmest and coldest quarters of the year (Bio1, Bio10, and Bio11), and

237 were principally located in southern France. However, for the acoustic dataset, the PCA clearly

238 discriminated between longitudes (for A.PC1) and latitudes (for A.PC2). In contrast, for the mist

239 net dataset, both M.PC1 and M.PC2 carried information about both latitude and longitude, with

240 high M.PC1 values representing places with low temperatures (Bio10, Bio11) located in northern

241 France. This is likely linked to the fact that the capture points are more spread along an east-west

242 axis while the acoustic circuits are more distributed along a north-south axis.

244 Mist net dataset

245 Using mist net capture data, we found a significant positive relationship between body size

246 (represented by forearm length) and the first principal component (M.PC1) (Table 2, Fig.3).

247 Therefore, larger individuals were captured at places characterized by high precipitation (Bio12,

248 Bio16), and a low temperature range (Bio7), principally located in northwestern France. We also

249 found that males were smaller than females (negative intercept, Table 2). This result is expected

250 since this species exhibits a female-biased sexual size dimorphism (see Appendix A3 and Dietz

251 et al., 2007). However, we did not find a significant relationship between the sex-ratio and 
252 M.PC1 or M.PC2 (estimates: $0.01 \pm 0.04$ and $0.02 \pm 0.05$, respectively and both $\mathrm{p}>0.7$ ), therefore

253 changes in sex ratio should not affect our main conclusions. Finally, we did not find an effect of

254 the date of measurement on body size; however, this was expected given that we analyzed only

255 adults, and corrected for the sex of the individuals.

256

257 Acoustic dataset

258 Using acoustic data, we found a significant positive relationship between characteristic

259 frequencies and the second principal component (A.PC2) (Table 2, Fig.3). Therefore, lower

260 frequencies (i.e., larger individuals (Barclay \& Brigham, 1991; Jones, 1999; Jakobsen et al.,

261 2013; Jung et al., 2014)) were related to places characterized by low temperatures (Biol and

262 Bio10) and a low temperature range (Bio7), principally located in northern France. The models

263 showed significant effects of the survey period and SlopeQCF. Characteristic frequencies were

264 higher when measured during the second survey period (August-September). Characteristic

265 frequencies were also higher for higher absolute values of SlopeQCF, i.e., for steeper signals,

266 harboring a more negative slope (Table 2). SlopeQCF was higher in cluttered habitats (Appendix

267 A2). When the local temperature during a recording session or the call abundance were not

268 included in the model, the results remained quantitatively comparable (Appendix, Table A5.1).

269 We also obtained similar results when using the date of recording instead of the survey period in

270 the models (Appendix A6). Neither our capture localities nor acoustic circuits were evenly 
271 distributed in space. However, the main results were maintained when the analyses were

272 conducted on spatial data subsets with high point densities (Appendix A4), and they were similar

273 for both mist net capture and acoustic datasets, thus suggesting that our overall results were

274 robust.

275

276 Discussion

277 Using acoustic data from a large-scale citizen science program, we found significant

278 relationships between characteristic frequencies of $P$. pipistrellus and geographic and climatic

279 variables. We detected lower frequencies, corresponding to larger body sizes, in colder regions

280 with low temperature variation. In parallel, our analysis using measurements of bat body size in

281 the field showed that larger bats were also captured in colder and wetter areas, with low

282 temperature variation. Our datasets did not cover the same regions: the acoustic dataset spans a

283 latitudinal gradient, while the mist-net dataset rather includes a longitudinal sampling. Despite

284 these differences, the two analyses showed similar results, which indicates that acoustic datasets

285 might be used to study large-scale patterns in body size.

286 Forearm length was mainly related to high precipitation, low seasonality, and low temperatures

287 occurring in sample areas in northwestern France. Lower characteristic frequencies (i.e., larger

288 body sizes) were mostly correlated with the low temperatures that occur in northern France. Our

289 result is in accordance with a previous study on P. pipistrellus conducted over a similar spatial 
290 extent to the present one (Stebbings, 1973). Furthermore, this pattern of body size increasing

291 with decreasing temperature and increasing humidity has also been found for Eptesicus fuscus, a

292 bat species from temperate zones (Burnett, 1983), and for Cynopterus sphinx, a tropical bat

293 species (Storz et al., 2001). More importantly, our results are also in accordance with

294 biogeographic rules, that predict increased body sizes at higher latitudes and in colder and wetter

295 climates (Bergmann's and James' rules: Bergmann, 1847; James, 1970).

Intraspecific variation in body size across a species range might be driven by several

mechanisms including adaptation to local climate (Endler, 1977; Cordero \& Epps, 2012) and

adaptive plasticity as a response to different environments and to resource availability during

early development (Henry \& Ulijaszek, 1996; Lindström, 1999; McNab, 2010). At this stage, the

drivers of any spatial patterns observed remain to be identified. While P. pipistrellus is a mobile

species with a broad and continuous distribution, a genetic structuring hypothesis cannot be ruled

out because such structuration has been observed within similar species (Kert \& Petit, 2005;

Moussy et al. 2013). A non exclusive alternative hypothesis to explain the observed pattern could

be the spatial difference in resource availability during the early stages of development. Future

research using genetic information and data on resource availability could help to assess the

relative importance of different drivers of body size variation in $P$. pipistrellus. 
309 spatial scales. For instance, characteristic frequencies during the second survey, i.e., in August-

310 September, were higher than in the first one. If frequency is linked with body size as expected

311 (Thiagavel et al., 2017), this pattern would indicate a higher proportion of smaller individuals in

312 the population during this period. This might be explained either by more intense male activity

313 (as they are smaller than the females), or by a higher proportion of young bats (which are smaller

314 than the adults) in August to September (Arthur \& Lemaire, 2015). We also found that

315 SlopeQCF was positively related to the characteristic frequency and was higher in cluttered

316 habitats; a result that has previously been described at the individual level (Kalko \& Schnitzler,

317 1993). Therefore, broad scale acoustic monitoring may also have the potentiality to enable the

318 detection of fine-scale behavioral adaptations to the local environment, such as vegetation

319 clutter.

320 In France, other species also emit calls with terminal frequencies between $41-52 \mathrm{kHz}(P$.

321 nathusii, P. kuhlii, P. pygmaeus, and Miniopterus schreibersi). Therefore, some identification

322 errors could have occurred due to overlap between acoustic repertoires. However, our dataset

323 contained few samples from the Mediterranean region; thus, the abundance of P. pygmaeus and

324 M. schreibersi, which are mostly present in the Mediterranean (Arthur and Lemaire, 2015)

325 should be very low in our dataset. $P$. kuhlii has lower terminal frequencies on average than $P$.

326 pipistrellus (Obrist et al., 2004; Barataud et al., 2015), but is much more abundant in the south

327 than in the north of France (Arthur \& Lemaire, 2015), which would contradict the observed 
328 pattern (larger individuals and lower calls in northern France). Therefore, even allowing for

329 errors in identification, potential confusion with other species should not significantly bias our

330 results.

331

332 Conclusion

333 Using bat characteristic frequencies collected by a citizen science program, we identified

334 apparent intraspecific large-scale variation in body size. This result was also supported by mist

335 net capture data and highlights new perspectives for the use of acoustic databases to explore

336 biological patterns at various spatial and temporal scales. In this context, characteristic

337 frequencies can be used as a proxy for body size, and because body size is also related to habitat

338 suitability and environmental filtering (Cisneros et al., 2014; Nash et al., 2014), they might

339 constitute useful indicators for the assessment of biodiversity states and trends. Further studies

340 might cover a larger geographic range focus on other bat species and explore deeply all the

341 potentialities of characteristic frequency measurements to address both fundamental questions,

342 such as the validity of the Bergmann rule, and applied ecological questions, such as the

343 relationship between habitat suitability or degradation and body size. Large-scale data from

344 citizen science programs might also benefit research projects that aim to assess the mechanisms

345 underlying biodiversity responses to global changes at the intraspecific level (Luo et al., 2014),

346 an urgent topic in the context of the current biodiversity crisis. 


\section{Acknowledgements}

349 The success of such long-term, large-scale surveys relies entirely on the continuous participation

350 of voluntary observers that we warmly thank. We are also deeply grateful to bat-workers for

351 providing mist net capture data. Names of bat-workers and volunteers are cited in the

352 Supplementary material of this paper Appendix A7, extended acknowledgements. We also thank

353 Robin Julien for help in analyzing acoustic data and two anonymous reviewers for helpful

354 comments and suggestions. 
356

357

358

359

360

361

362

363

364

365

366

367

368

369

370

371

372

373

374

375

376

377

378

\section{References}

Arthur L, Lemaire M. 2015. Les Chauves-souris de France, Belgique, Luxembourg et Suisse. Deuxième édition. Paris: Muséum national d'Histoire naturelle, Mèze: Biotope,

Ashton KG, Tracy MC, de Queiroz, A. 2000. Is Bergmann's rule valid for mammals ? American Naturalist 156:390-415. DOI:10.1086/303400

Barataud M, Cockle-Betian A, Limpens H, Tupinier Y. 2015. Acoustic ecology of European bats: species identification, study of their habitats and foraging behaviour. Mèze: Biotope Éditions.

Barclay RMR, Brigham RM. 1991. Prey detection, dietary niche breadth, and body size in bats :

Why are aerial insectivorous bats so small ? American Naturalist 137:693-703.

DOI: $10.1086 / 285188$

Bardeli R, Wolff D, Kurth F, Koch M, Tauchert K-H, Frommolt K-H. 2010. Detecting bird sounds in a complex acoustic environment and application to bioacoustic monitoring. Pattern Recognition Letters 31:1524-1534. DOI:10.1016/j.patrec.2009.09.014

Barnagaud JY, Daniel Kissling W, Sandel B, Eiserhardt WL, Şekercioğlu ÇH, Enquist BJ, Tsirogiannis C, Svenning, JC. 2014. Ecological traits influence the phylogenetic structure of bird species co-occurrences worldwide. Ecology Letters, 17:811-820.

Bates D, Maechler M, Bolker B, Walker S. 2015. Fitting Linear Mixed-Effects Models Using lme4. Journal of Statistical Software. 67:1-48. doi:10.18637/jss.v067.i01.

Bergmann C. 1847. Über die verhältnisse der Wärmeökonomie der Thiere zu ihrer Grösse. Göttinger Study 1:595-708.

Binary Acoustic Technology LLC. 2009. Scan'R software manual - Snapshot Characterization and Analysis. 
379 Britzke ER. 2004. Designing monitoring programs using frequency-division bat detectors: active 380 versus passive sampling. In Bat Echolocation Research: Tools, Techniques, and Analysis, 381 Brigham RM, Kalko EKV, Jones G, Parsons S, Limpens HJGA, Eds. Bat Conservation 382 International, Austin, TX

383 Brown JH, 1995, Macroecology. University of Chicago Press, Chicago, USA

384 Brown JH, Maurer BA. 1989. Macroecology: the division of food and space among species on 385 continents. Science 243.4895:1145-1150.

386 Burnett CD. 1983. Geographic and climatic correlates of morphological variation in Eptesicus 387 fuscus. Journal of Mammalogy 64:437-444. DOI:10.2307/1380356

388 Cisneros LM, Burgio KR, Dreiss LM, Klingbeil BT, Patterson BD, Presley SJ, Willig MR. 2014. 389 Multiple dimensions of bat biodiversity along an extensive tropical elevational gradient. 390 Journal of Animal Ecology 83:1124-1136. DOI:10.1111/1365-2656.12201

391 Clauss M, Dittmann MT, Müller DWH, Meloro C, Codron D. 2013. Bergmann's rule in 392 mammals: a cross-species interspecific pattern. Oikos 122:1465-1472. DOI:10.1111/j.1600$393 \quad 0706.2013 .00463 . x$

394 Cordero G, Epps CW. 2012. From desert to rainforest: phenotypic variation in functionally 395 important traits of Bushy-Tailed Woodrats (Neotoma cinerea) across two climatic extremes. 396 Journal of Mammalian Evolution 19:135-153. DOI:10.1007/s10914-012-9187-0.

397 Davidson-Watts I, Walls S, Jones G. Differential habitat selection by Pipistrellus pipistrellus and 398 Pipistrellus pygmaeus identifies distinct conservation needs for cryptic species of 399 echolocating bats. 2006. Biological conservation 133: 118-127.

400 Dietz C, von Helversen O. 2004. Illustrated identification key to the bats of Europe. Electron.

$401 \quad$ Publ. Version 1.0. Available at 

https://www.researchgate.net/publication/228985859_Illustrated_identification_key_to_the_ bats_of_Europe (accessed 19 December 2017)

404 Dietz C, Von Helversen O, Nill D. 2007. Handbuch der fledermäuse Europas und 405 nordwestafrikas, Franckh-Kosmos Verlags GmbH. Stuttgart.

406 Endler, J.A., 1977. Geographic variation, speciation, and clines. Princeton University Press.

407 Freckleton RP, Harvey PH, Pagel M. 2003. Bergmann's Rule and body size in Mammals. $408 \quad$ American Naturalist 161:821-825. DOI:10.1086/374346.

409 Gillooly JF, Ophir AG. 2010. The energetic basis of acoustic communication. Proceedings of the $410 \quad$ Royal Society B-Biological Sciences 277:1325-31. DOI:10.1098/rspb.2009.2134.

411 Hassall C, Keat S, Thompson DJ, Watts PC. 2014. Bergmann's rule is maintained during a rapid 412 range expansion in a damselfly. Global Change Biology 20: 475-482.

413 DOI:10.1111/gcb.12340

414 Henry CJK, Ulijaszek SJ. 1996. Long-term consequences of early environment: growth, 415 development and the lifespan developmental perspective. Cambridge University Press.

416 Hijmans RJ, Cameron SE, Parra JL, Jones PG, Jarvis A. 2005. Very high resolution interpolated 417 climate surfaces for global land areas. International Journal of Climatology 25:1965-1978.

418 Jacobs DS, Barclay RMR, Walker MH. 2007. The allometry of echolocation call frequencies of 419 insectivorous bats: why do some species deviate from the pattern? Oecologia 152:583-94. 420 DOI:10.1007/s00442-007-0679-1.

421 Jakobsen L, Ratcliffe JM, Surlykke A. 2013. Convergent acoustic field of view in echolocating 422 bats. Nature 493:93-6. DOI:10.1038/nature11664.

423 James FC. 1970. Geographic size variation in birds and its relationship to climate. Ecology $424 \quad$ 51:365-390. DOI:10.2307/1935374. 
425 Johnston DW, McDonald M, Polovina J, Domokos R, Wiggins S, Hildebrand J. 2008. Temporal 426 patterns in the acoustic signals of beaked whales at Cross Seamount. Biology Letter 4:208211. DOI:10.1098/rsbl.2007.0614.

428

429

430

431

432

434

435

436

437

438

439

440

441

442

443

444

445

446

Jones G. 1999. Scaling of echolocation call parameters in bats. J. Exp. Biol. 202, 3359-67.

Jones G, van Parijs SM, Vanparijs S. 1993. Bimodal echolocation in pipistrelle bats: are cryptic species present? Proceedings of the Royal Society B-Biological Sciences 251:119-25. DOI:10.1098/rspb.1993.0017.

Jones KE, Russ JA, Bashta A-T, Bilhari Z, Catto C, Csősz I, Gorbachev A, Győrfi P, Hughes, A, Ivashkiv I, Koryagina N, Kurali A, Langton S, Collen A, Margiean G, Pandourski I, Parsons S, Prokofev I, Szodoray-Paradi A, Szodoray-Paradi F, Tilova E, Walters CL, Weatherill A, Zavarzin O, 2013. Indicator bats program: a system for the global acoustic monitoring of bats, In: Biodiversity Monitoring and Conservation. Wiley-Blackwell, 211-247. DOI:10.1002/9781118490747.ch10.

Jung K, Molinari J, Kalko EV. 2014. Driving factors for the evolution of species-specific echolocation call design in new world free-tailed bats (molossidae). PLoS One 9:e85279. DOI:10.1371/journal.pone.0085279.

Kalko EV, Schnitzler, H-U. 1993. Plasticity in echolocation signals of European pipistrelle bats in search flight: implications for habitat use and prey detection. Behavioral Ecology and Sociobiology 33:415-428. DOI:10.1007/BF00170257.

Kerbiriou C, Azam C, Touroult J, Marmet J, Julien JF, Pellissier V. 2018. Common bats are more abundant within Natura 2000 areas. Biological Conservation 217:66-74. DOI: 10.1016/j.biocon.2017.10.029. 
447 Kuznetsova A, Brockhoff PB, Christensen RHB. 2017. ImerTest Package: Tests in Linear Mixed $448 \quad$ Effects Models. Journal of Statistical Software. 82:1-26. doi: 10.18637/jss.v082.i13

449 Law BS, Reinhold L, Pennay M. 2002. Geographic Variation in the Echolocation Calls of 450 Vespadelus spp. (Vespertilionidae) from New South Wales and Queensland, Australia. Acta $451 \quad$ Chiropterologica 4:201-215. DOI:10.3161/001.004.0208.

452 Lindström J. 1999. Early development and fitness in birds and mammals. Trends in Ecology and 453 Evolution 14:343-348. DOI:10.1016/S0169-5347(99)01639-0.

454

455

456

457

458

459

460

461

462

463

464

465

466

467

468

Luo J, Koselj K, Zsebők S, Siemers BM, Goerlitz HR. 2014. Global warming alters sound transmission: differential impact on the prey detection ability of echolocating bats. Journal of the Royal Society Interface 11:20130661. DOI: 10.1098/rsif.2013.0961.

Machac A, Janda M, Dunn RR, Sanders NJ. 2011. Elevational gradients in phylogenetic structure of ant communities reveal the interplay of biotic and abiotic constraints on diversity. Ecography 34: 364-371. DOI:10.1111/j.1600-0587.2010.06629.x

Mayer F, von Helversen O. 2001. Cryptic diversity in European bats. Proceedings of the Royal Society B-Biological Sciences 268:1825-1832. DOI: 10.1098/rspb.2001.1744.

McNab BK. 2010. Geographic and temporal correlations of mammalian size reconsidered: a resource rule. Oecologia 164:13-23. DOI: 10.1007/s00442-010-1621-5.

Meiri S, Dayan T. 2003. On the validity of Bergmann's rule. Journal of Biogeography 30:331351. DOI:10.1046/j.1365-2699.2003.00837.x.

Mitchell-Jones AJ, Amori, G, Bogdanowicz W, Krystufek B, Reijnders PJH, Spitzenberger F, Stubbe M, Thissen JBM, Vohralik V, Zima J. 1999. The atlas of European mammals, T \& A D Po. ed, Poyser Natural History Series. Academic Press, London. 
469 MNHN \& SFEPM. 2015. Charte de déontologie pour la pratique de la capture des Chiroptères, $470 \quad$ Plan national d'actions Chiroptères 2009-2013, version 22015

471 Murray KL, Britzke ER, Robbins LW. 2001. Variation in search-phase calls of bats. Journal of 472 Mammalogy 82:728-737. DOI: 10.1644/1545-1542(2001)082<0728:VISPCO>2.0.CO;2.

473

474

475

476

477

478

479

480

481

482

483

484

485

486

487

488

489

490

491

Nash KL, Allen CR, Barichievy C, Nyström M, Sundstrom S, Graham NJ. 2014. Habitat structure and body size distributions: cross-ecosystem comparison for taxa with determinate and indeterminate growth. Oikos 123:971-983. DOI: 10.1111/oik.01314.

Necknig V, Zahn A. 2011. Between-species jamming avoidance in Pipistrelles? Journal of Comparative Physiology A-Neuroethology Sensory Neural and Behavioral Physiology 197:469-73. DOI: 10.1007/s00359-010-0586-5.

Newson SE, Bas Y, Murray A, Gillings S. 2017. Potential for coupling the monitoring of bushcrickets with established large-scale acoustic monitoring of bats. Methods in Ecology and Evolution 8:1051-1062. DOI: 10.1111/2041-210X.12720.

Newson SE, Evans HE, Gillings S. 2015. A novel citizen science approach for large-scale standardised monitoring of bat activity and distribution, evaluated in eastern England. Biological Conservation 191:38-49. DOI: 10.1016/j.biocon.2015.06.009.

Norberg U. 1981. Allometry of bat wings and legs and comparison with bird wings. Philosophical Transactions of the Royal Society B: Biological Sciences 292:359-398.

O'Farrell MJ, Corben C, Gannon WL. 2000. Geographic variation in the echolocation calls of the hoary bat (Lasiurus cinereus). Acta Chiropterologica 2:185-196.

Obrist MK, Boesch R, Flückiger PF. 2004. Variability in echolocation call design of 26 Swiss bat species: consequences, limits and options for automated field identification with a synergetic pattern recognition approach. Mammalia 68:307-322. 
492 Penone C, Le Viol I, Pellissier V, Julien J-F, Bas Y, Kerbiriou C. 2013. Use of large-scale

493 acoustic monitoring to assess anthropogenic pressures on orthoptera communities.

494 Conservation Biology 27:979-987. DOI: 10.1111/cobi.12083.

495 Peters RH. 1986. The ecological implications of body size. Cambridge University Press. 26:549-

496 558. DOI: 10.1046/j.1365-2699.1999.00303.x.

497 R Core Team. 2013. R: A language and environment for statistical computing. R Foundation for $498 \quad$ Statistical Computing, Vienna, Austria.

499 Riede K. 1998. Acoustic monitoring of Orthoptera and its potential for conservation. Journal of $500 \quad$ Insect Conservation 2:217-223.

501 Rosenzweig ML. 1968. The strategy of body size in mammalian carnivores. American Midland $502 \quad$ Naturalist 80:299-315. DOI: 10.2307/2423529.

503 Russo D, Jones G, Mucedda M. 2001. Influence of age, sex and body size on echolocation calls

504 of Mediterranean and Mehely's horseshoe bats, Rhinolophus euryale and R. mehelyi

505 (Chiroptera: Rhinolophidae). Mammalia 65:429-436. DOI: 10.1515/mamm.2001.65.4.429

506 Stebbings RE. 1973. Size clines in the bat Pipistrellus pipistrellus related to climatic factors.

507 Periodicum Biologorum 75:189-194.

508 Ulanovsky N, Fenton MB, Tsoar A, Korine C. 2004. Dynamics of jamming avoidance in 509 echolocating bats Proceedings of the Royal Society B-Biological Sciences 271:1467-75.

$510 \quad$ DOI: $10.1098 /$ rspb.2004.2750.

511 Walters CL, Freeman R, Collen A, Dietz C, Fenton M, Jones G, Obrist MK, Puechmaille SJ,

512 Sattler T, Siemers BM, Parsons S, Jones KE. 2012. A continental-scale tool for acoustic

513 identification of European bats. Journal of Applied Ecology 49:1064-1074.

$514 \quad$ DOI:10.1111/j.1365-2664.2012.02182.x. 
515 Yom-Tov Y, Geffen E. 2006. Geographic variation in body size: The effects of ambient

516 temperature and precipitation. Oecologia 148:213-218. DOI:10.1007/s00442-006-0364-9.

517 


\section{Table $\mathbf{1}$ (on next page)}

Variable loadings resulting from principal components analysis of geographic and climatic variables for the mist net and acoustic datasets.

Only the first two PCs are shown and were used for further analysis. 
1 Table 1: Variable loadings resulting from principal components analysis of geographic and 2 climatic variables for the mist net and acoustic datasets. Only the first two PCs are shown and were 3 used for further analysis.

4

\begin{tabular}{llrrrr} 
& & \multicolumn{2}{c}{ Mist-net dataset } & \multicolumn{2}{c}{ Acoustic dataset } \\
& Description & M.PC1 & M.PC2 & A.PC1 & A.PC2 \\
\hline X & Longitude & -0.40 & -0.26 & -0.44 & 0.05 \\
Y & Latitude & 0.25 & -0.41 & -0.01 & -0.58 \\
Bio1 & Annual mean temperature & 0.01 & 0.65 & 0.25 & 0.47 \\
Bio7 & Annual temperature range & -0.45 & -0.07 & -0.37 & 0.34 \\
Bio10 & Mean temperature of the warmest quarter & -0.39 & 0.34 & -0.20 & 0.54 \\
Bio11 & Mean temperature of the coldest quarter & 0.33 & 0.46 & 0.44 & 0.07 \\
Bio12 & Annual precipitation & 0.37 & -0.10 & 0.42 & 0.16 \\
Bio16 & Precipitation of the wettest quarter & 0.42 & -0.04 & 0.45 & 0.07
\end{tabular}




\section{Table 2 (on next page)}

Results of the fixed effects from linear mixed-effects models for the relationships between forearm length (from mist net data), characteristic frequencies (from acoustic data) and climatic and geographic variables represented by principal components.

SlopeQCF: slope of the quasi-constant-frequency. 
1 Table 2: Results of the fixed effects from linear mixed-effects models for the relationships

2 between forearm length (from mist net data), characteristic frequencies (from acoustic data) and

3 climatic and geographic variables represented by principal components. SlopeQCF: slope of the

4 quasi-constant-frequency.

5

\begin{tabular}{lrrrr} 
Forearm length $(\mathbf{n = 1 3 5 1})$ & Estimate & SE & t-value & $\boldsymbol{P}$ \\
\hline Male & -0.76 & 0.05 & -15.74 & $<0.000$ \\
Day of the year & -0.00 & 0.00 & -0.33 & 0.744 \\
M.PC1 & 0.05 & 0.01 & 3.42 & $<0.000$ \\
M.PC2 & -0.02 & 0.02 & -0.87 & 0.385
\end{tabular}

Characteristic frequency $(n=4783)$

$\begin{array}{lrrrr}\text { SlopeQCF } & -0.72 & 0.04 & -27.62 & <0.000 \\ \text { Second Survey } & 0.68 & 0.06 & 11.76 & <0.000 \\ \text { Call abundance } & -0.00 & 0.00 & -0.25 & 0.806 \\ \text { A.PC1 } & -0.00 & 0.03 & -0.13 & 0.900 \\ \text { A.PC2 } & 0.11 & 0.03 & 3.10 & 0.003\end{array}$

6 


\section{Figure 1 (on next page)}

Map of France with locations where bat where bats were captured (mist net dataset, black points), and recorded (acoustic dataset, red points) 


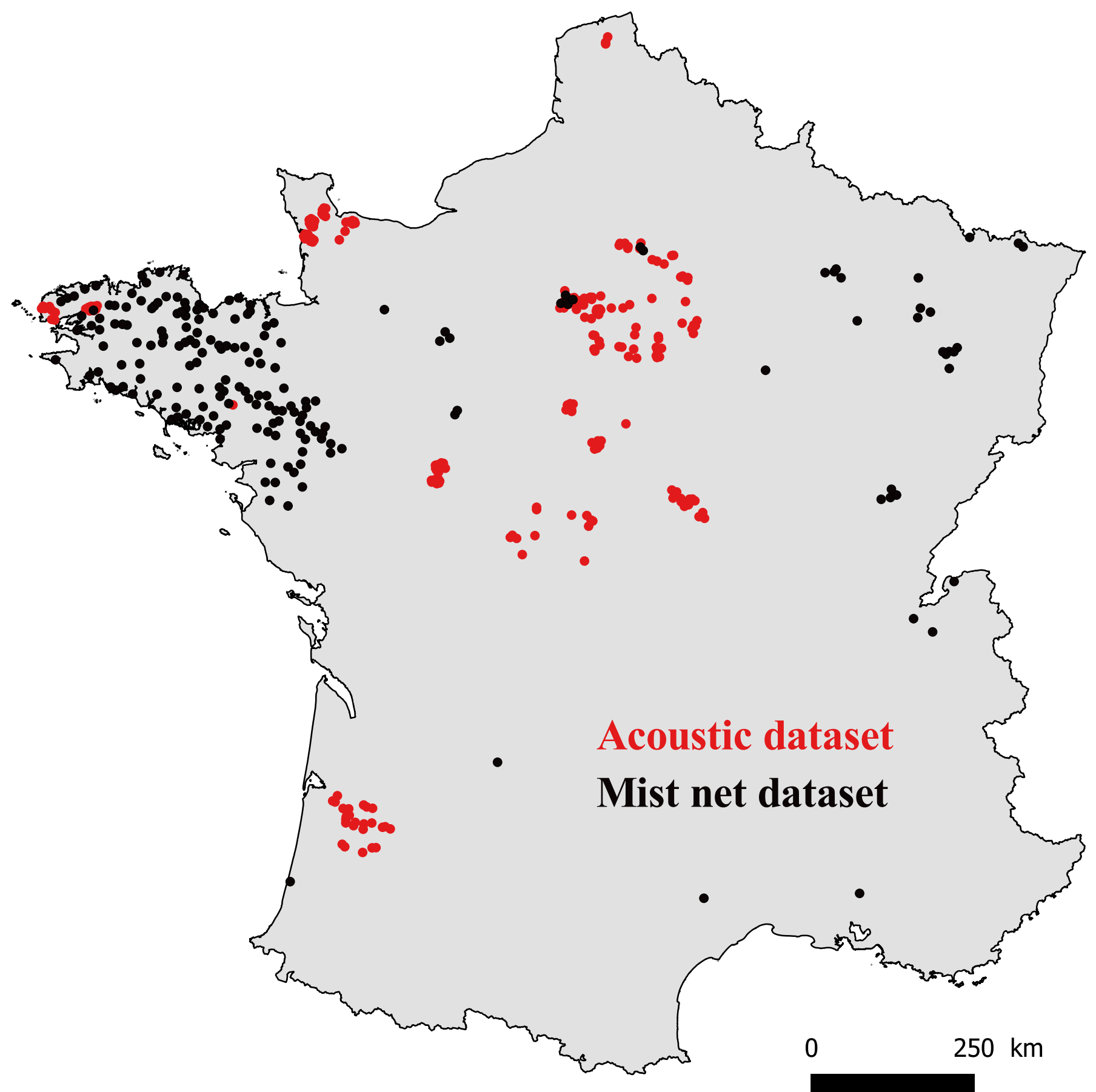




\section{Figure 2 (on next page)}

First two principal components resulting from PCA for geographic and climatic variables for mist net (a) and acoustic (b) datasets.

Percentage values represent proportion of the total variation explained by each component. For variables descriptions see Table 1. 


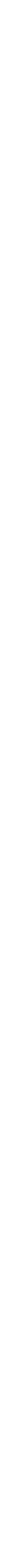




\section{Figure 3 (on next page)}

Relationships between forearm length (a) and characteristic frequency (b) and the principal components resulting from PCA (PC1 and PC2) that were found to be significant in linear mixed-effects models.

The lines represent fitted linear models with 95\% confidence region for the regression fit. 

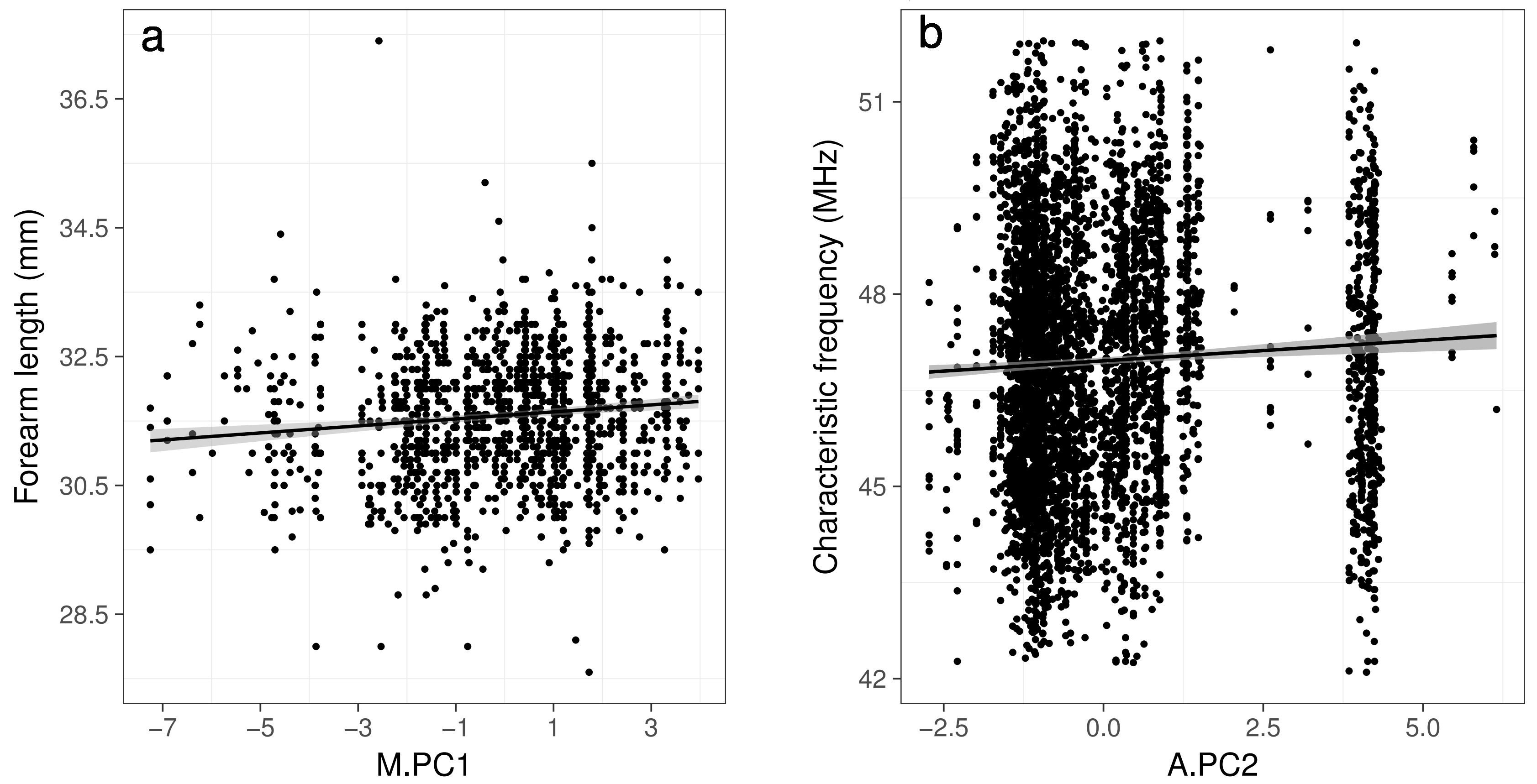